\title{
Partial agonistic effect of cetuximab on epidermal growth factor receptor and Src kinase activation in triple-negative breast cancer cell lines
}

\author{
HAKAN GURDAL $^{1}$, MATILDA MERVE TUGLU ${ }^{1}$, SABER YARI BOSTANABAD ${ }^{2}$ and BAŞAK DALKILIÇ ${ }^{1}$ \\ ${ }^{1}$ Department of Medical Pharmacology, Faculty of Medicine, University of Ankara, 06100 Ankara; \\ ${ }^{2}$ Biotechnology Institute of Ankara University, 06110 Ankara, Turkey
}

Received August 23, 2018; Accepted January 15, 2019

DOI: $10.3892 /$ ijo.2019.4697

\begin{abstract}
Cetuximab is a monoclonal antibody developed to inhibit the binding of growth factors and the subsequent activation of epidermal growth factor receptor (EGFR). Triple-negative breast cancer (TNBC) is resistant to cetuximab treatment. The aim of the present study was to examine the partial agonistic properties of cetuximab, which not only blocks ligand binding, but also partially triggers EGFR activation, which may lead to cetuximab resistance in TNBC. The phosphorylation of growth factor receptors and their signalling pathways were evaluated by determining the phosphorylation of EGFR, insulin-like growth factor receptor (IGF-1R), vascular endothelial growth factor receptor (VEGFR)-2, Src kinase, phosphoinositide-3-kinase (PI3K), extracellular signal-regulated kinase (ERK1/2) and serine/threonine-specific protein kinase (Akt) and the degradation of EGFR, and by assessing the morphology and proliferation of MDA-MB-231 and MDA-MB-468 cells. Cetuximab treatment led to the phosphorylation of EGFR, VEGFR-2, IGF-1R and downstream signalling
\end{abstract}

Correspondence to: Professor Hakan Gurdal, Department of Medical Pharmacology, Faculty of Medicine, University of Ankara, 6 Adnan Saygun Street, Sihhiye, 06100 Ankara, Turkey

E-mail: gurdal@medicine.ankara.edu.tr

Abbreviations: Akt, serine/threonine-specific protein kinase; EGFR, epidermal growth factor receptor; ERK1/2, extracellular signal-regulated kinase $1 / 2$; IGF-1R, insulin-like growth factor receptor; GAPDH, glyceraldehyde 3-phosphate dehydrogenase; MAPK, mitogen-activated protein kinase; SDS-PAGE, sodium dodecyl sulphate-polyacrylamide gel electrophoresis; PI3K, phosphoinositide-3-kinase; TNBC, triple-negative breast cancer; VEGFR, vascular endothelial growth factor receptor

Key words: epidermal growth factor receptor, breast cancer, cetuximab, partial agonist, Src kinase, insulin-like growth factor receptor, vascular endothelial growth factor receptor, transactivation, monoclonal antibody, MDA-MB231, MDA-MB-468, PP2, triple-negative breast cancer molecules, Src kinase and PI3K in these cells, as well as Akt in the MDA-MB-231 cells. The cetuximab-mediated phosphorylation of IGF-1R, VEGFR-2 and Akt was inhibited by the EGFR kinase inhibitor, AG1478, and the Src kinase inhibitor, PP2. Cetuximab treatment led to the degradation of EGFR. The cetuximab-induced phosphorylation and EGFR degradation were less prominent compared with those induced by EGF. Cetuximab partially inhibited EGF-mediated responses. Cetuximab, similar with EGF, altered cellular morphology in a serum-free medium. In both cell lines, the Src kinase inhibitor enhanced the cetuximab-induced anti-proliferative response. These results indicate that cetuximab exerts a partial agonistic effect on EGFR, which activates Src kinase and subsequently transactivates IGF-1R and VEGFR-2. This partial agonistic property is likely one of the mechanisms underlying the resistance of TNBC to cetuximab.

\section{Introduction}

Epidermal growth factor (EGF) receptor (EGFR) is a receptor tyrosine kinase (RTK) and a member of the ErbB family. EGFR agonists, such as EGF, transforming growth factor- $\alpha$ and epiregulin, bind to the extracellular domain of EGFR and cause the homodimerization or heterodimerization of Erb family receptors, which leads to the phosphorylation of intracellular EGFR sites, such as the Tyr1173 and Tyr1068 residues. The phosphorylation of these sites activates signalling pathways, such as the RAS/mitogen-activated protein kinase (MAPK), phosphoinositide-3-kinase (PI3K)/serine/threonine-specific protein kinase (Akt) and Janus kinase/signal transducer and activator of transcription (Jak/Stat) pathways (1-5). The activation of these pathways mediates cellular proliferation and transformation, which may cause cancer occurrence, growth, invasion and metastasis.

Triple-negative breast cancer (TNBC) does not express human epidermal growth factor receptor type (HER)2, progesterone receptor (PR) or oestrogen receptor (ER), but does express EGFR $(6,7)$. There is evidence that EGFR overexpression is associated with an aggressive phenotype and a poor clinical outcome in breast cancers, including TNBC (8-12). 
Therefore, blocking the EGFR-mediated signalling pathway is a therapeutic target for treating EGFR-expressing cancer types, such as TNBC. Cetuximab (CTX) was developed to bind to the extracellular domain of EGFR, which blocks the binding of EGF and inhibits the subsequent phosphorylation and activation of EGFR and downstream signalling pathways, such as RAS/MAPK, PI3K/Akt and Jak/Stat (13-15). CTX has been used in the treatment of metastatic colorectal cancer and head and neck squamous cell carcinoma, both as monotherapy and in combination with chemotherapy and radiotherapy $(14,16)$.

However, certain types of cancer, such as TNBC and lung and colon cancer are resistant to CTX treatment $(4,16,17)$. Primary and acquired resistance to anti-EGFR treatment has been described (4), with several studies reporting that genetic alterations in key regulators, such as KRAS, BRAF, phosphatase and tensin homologue (PTEN) and phosphoinositide-3-kinase, catalytic subunit $\alpha$ (PIK3CA), in the signalling pathways of RTKs are an important mechanism underlying resistance to anti-EGFR treatment $(4,6,17-20)$. These alterations lead to the activation of RAS/MAPK and PI3K/Akt, independently of the activation status of growth factor receptors. As a result, the blocking of EGFR by antibodies or tyrosine kinase inhibitors becomes ineffective in shutting down these signalling pathways. TNBC cells, such as MDA-MB-231, harbour mutations in KRAS and BRAF, whereas MDA-MB-468 cells do not have the Akt signalling pathway-inhibiting gene, PTEN, as a tumour suppressor (21). Hence, these cell lines often exhibit resistance to anti-EGFR treatment. However, the mutations in KRAS, BRAF, PTEN and PIK3CA cannot fully explain this resistance, since it is also observed in wild-type breast and colon cancer cells, which do not harbour these mutations $(20,22)$.

The ligands of RTKs possess partial agonist properties, which cause homo- or heterodimer formation and, subsequently, receptor phosphorylation and activation (23). Some antibodies directed against RTKs to block the binding of growth factors may also act as partial agonists (24-26). One study evaluating the targeting strategies of RTKs emphasised that the binding of an antibody with partial agonist properties to the receptor may cause phosphorylation, which triggers the ubiquitination and degradation of the receptor, resulting in irreversible antagonism of the RTK (26), the inhibition of the malignant response and cell proliferation, which may lead to a significant anticancer response in cancer cells.

On the other hand, the partial agonistic action of an antibody on the RTK may induce the phosphorylation of receptor tyrosine residues, activating PI3K/Akt, RAS/MAPK and PLC $\gamma / \mathrm{PKC}$, similar to EGF or a full agonist. Therefore, a partial agonist antibody may lead to RTK activation, which may cause resistance to this antibody in cancer cells. For example, trastuzumab binds to ErbB2, induces phosphorylation and exerts an agonistic effect on this receptor (27-29). Yoshida et al (30) demonstrated that matuzumab and CTX activated EGFR by inducing the phosphorylation of the Tyr845, Tyr1068 and Tyr1173 residues in the non-small-cell lung cancer cell lines, H292 and H460. Similarly, Raben et al (31) observed that CTX induced the phosphorylation of the Tyr845, Tyr992 and Tyr1068 residues of EGFR in H322 and H292 cells. Furthermore, CTX treatment has been shown to enhance the phosphorylation of EGFR Tyr845 residues in MDA-MB-231 cells (32) and Tyr1068 in MDA-MB-468 cells (33).

The aim of the present study was to examine the partial agonistic effect of CTX on EGFR in the TNBC cell lines, MDA-MB-231 and MDA-MB-468. For this purpose, by treating TNBC cells with EGF or CTX, we measured the phosphorylation levels of EGFR (Tyr1173), PI3K, Akt, extracellular signal-regulated kinase (ERK)1/2 and Src kinase, the cellular level of EGFR and cellular morphology, using impedance measurement as an indication of RTK activity. Since the agonistic action on EGFR may lead to the transactivation or cross-activation of insulin-like growth factor receptor (IGF-1R) and vascular endothelial growth factor receptor (VEGFR)-2 (34,35), the phosphorylation status of these receptors with CTX or EGF treatment of TNBC cells was also determined. Finally, the anti-proliferative response of the cells to CTX was evaluated in the presence or absence of the Src kinase inhibitor, PP2, which inhibits the partial agonist action of CTX on EGFR.

\section{Materials and methods}

Reagents and antibodies. The EGFR kinase inhibitor, AG1478, the PI3K inhibitor, LY294002 [2-(4-morpholinyl)-8-phenyl-1(4H)-benzopyran-4-one hydrochloride], the Src kinase inhibitor, PP2 [4-amino-3-(4-chlo rophenyl)-1-(t-butyl)-1H-pyrazolo[3,4-d]pyrimidine], EGF and CTX were obtained from Sigma-Aldrich, Merck KGaA (Darmstadt, Germany). The antibodies used were as follows (dilution, catalogue number, host and clonality used for western blot analysis): p-VEGFR-2-Tyr1175 (1:1,000, 3770, rabbit monoclonal), p-Src-Tyr416 (1:1,000, 2101, rabbit polyclonal) from Cell Signalling Technology, Inc., Danvers, MA, USA; p-EGFR-Tyr1173 (1:1,000, sc-12351-R, rabbit polyclonal),EGFR (1:1,000, sc-53274, mouse monoclonal), p-IGF-1R-Tyr1161 (1:1,000, sc-101703, rabbit polyclonal), p-Erk1/2 (1:5,000, sc-136521, mouse monoclonal), ERK1/2 (1:1,000, sc-514302, mouse monoclonal), p-Akt-Ser473 (1:1,000, sc-7985, rabbit polyclonal), Akt (1:1,000, sc-8312, rabbit polyclonal), p-PI3K $(1: 1,000$, sc-12929, goat polyclonal), GAPDH $(1: 5,000$, sc-47724, mouse monoclonal), mouse anti-rabbit $(1: 10,000$, sc-2357), rabbit anti-goat IgG-HRP (1:10,000, sc-2768) and donkey anti-mouse IgG-HRP (1:10,000, sc-2314) all from Santa Cruz Biotechnology Inc. (Santa Cruz, CA, USA). In all control experiments, the cells were incubated with the corresponding dilution of solvent used for the ligand.

Cell culture, treatments, protein isolation and western blot analysis. The MDA MB 231 and MDA MB 468 TNBC cell lines, which are negative for ER, PR and HER2, but positive for EGFR, were employed in this study. The cell lines were obtained from the American Type Culture Collection (Manassas, VA, USA). The MDA-MB-231 and MDA-MB-468 cells were grown in $75-\mathrm{cm}^{2}$ non-treated cell culture flasks (Corning, Tewksbury, MA, USA) in Dulbecco's modified Eagle's medium and Eagle's minimal essential medium, respectively, enriched with $10 \%$ foetal bovine serum and $1 \%$ penicillin/streptomycin at $5 \% \mathrm{CO}_{2}, 37^{\circ} \mathrm{C}$, with $90-95 \%$ humidity. For each experiment, the cells $\left(2.5 \times 10^{5}\right.$ 

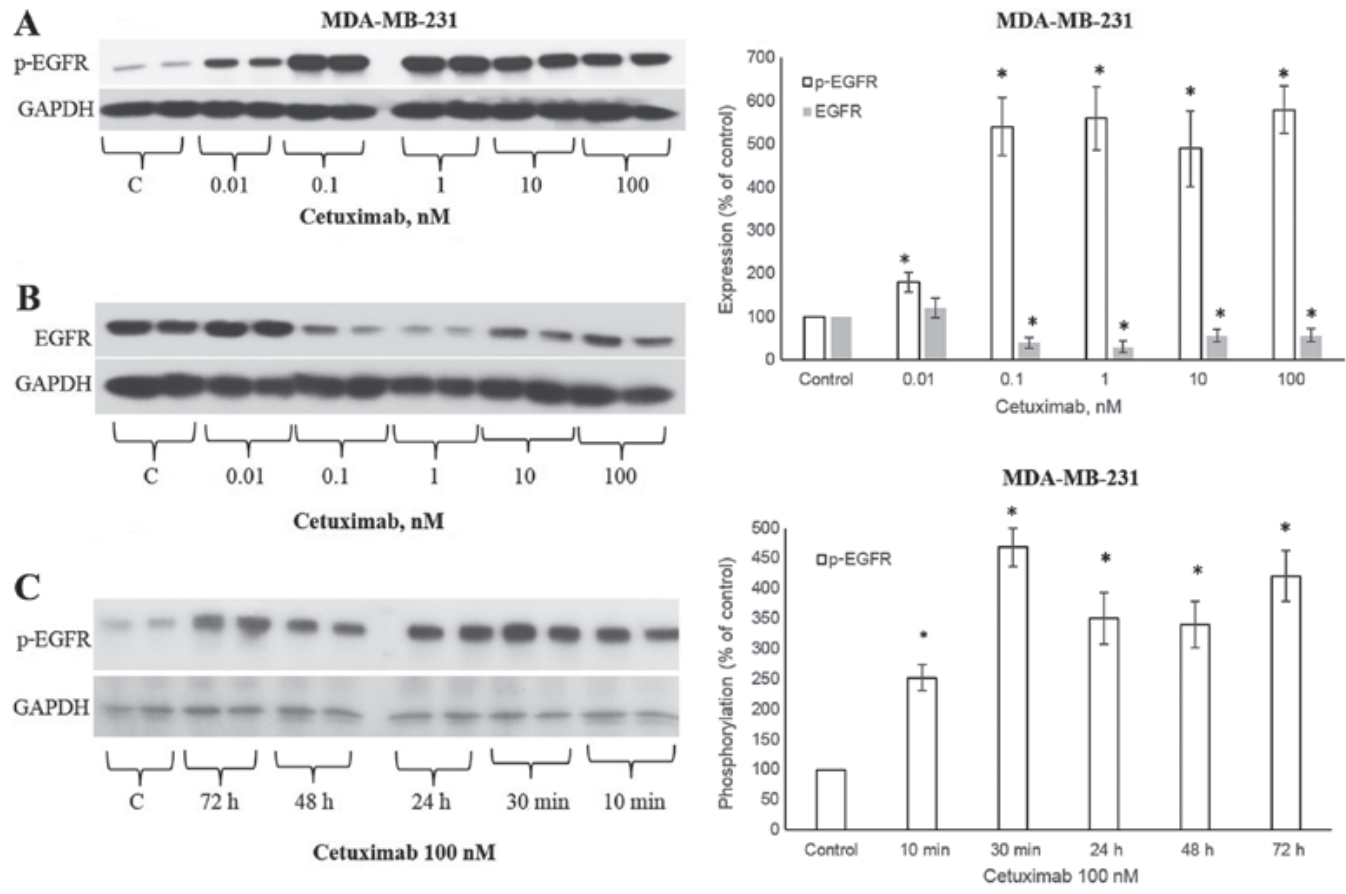

Figure 1. Cetuximab leads to EGFR phosphorylation in MDA-MB-231 cells. Treatment of the cells with cetuximab $(2 \mathrm{~h})$ at concentrations of $0.01,0.1,1$, 10 and $100 \mathrm{nM}$ (A) increased EGFR phosphorylation and (B) decreased EGFR levels. (C) CTX-stimulated phosphorylation was observable after 10 min of incubation at the $100 \mathrm{nM}$ concentration and persisted for $72 \mathrm{~h}$ in the MDA-MB-231 cells. Representative western blot bands for p-EGFR and EGFR are presented along with two replicate bands for the control (indicated by ' $\mathrm{C}$ '), and for the treatment groups as various concentrations of CTX (A and B) and for the treatment groups in different treatment periods with CTX (C). Since CTX decreases EGFR levels, GAPDH bands are presented as a control of the loading amount of protein. Band intensities were normalized to GAPDH and presented as a percentage of phosphate buffered saline-treated control cells. Data are presented as the means \pm standard error of the mean, $n=4-5$ experiments. ${ }^{~} \mathrm{P}<0.05$ vs. the control cells. CTX, cetuximab; EGFR, epidermal growth factor receptor.

cells/well) were plated in 6-well plates and treated with CTX $(0.01,0.1,1,10$ or $100 \mathrm{nM})$ or EGF $(1 \mathrm{nM})$ on the third day following overnight serum starvation. The concentration of ligands and the duration of cell treatment are specified in the results section. In some experiments, prior to CTX or EGF stimulation, the cells were pre-treated with one of the following inhibitors: AG1478 $(10 \mu \mathrm{M})$, LY294002 $(10 \mu \mathrm{M})$ or PP2 $(10 \mu \mathrm{M})$ for $30 \mathrm{~min}$. Following stimulation, the cells were immediately placed on ice and washed with ice-cold phosphate-buffered saline and homogenised in $100 \mu \mathrm{l}$ lysis buffer (Roche Molecular Diagnostics, Mannheim, Germany) containing 1\% Nonidet P40, $0.02 \mathrm{M}$ sodium orthovanadate and protease inhibitors. Following homogenization, the cells were incubated for $15 \mathrm{~min}$ and centrifuged at 5,000 x g for 5 min at $4^{\circ} \mathrm{C}$. After collecting the supernatant, the protein concentration was determined using the Bradford protein assay and the samples were stored at $-80^{\circ} \mathrm{C}$. Electrophoresis and western blot analysis were performed as previously described (36). Band intensities were corrected against t-ERK1/2, t-AKT or GAPDH expression. As a control of the loading amount of protein, GAPDH bands were used and the band intensities of p-EGFR, p-IGF-1R or p-VEGFR-2 were corrected against the GAPDH bands. The band intensities of EGFR, IGF-1R and VEGFR-2 were not used for the corrections, due to internalization and/or degradation of these receptors following ligand stimulation.

Real-time cellular morphology and cell proliferation assay by impedance measurements. These assays were performed as previously described (37-39), using the xCelligence Real-Time Cell Analyzer (RTCA) DP system (ACEA Biosciences, Inc., San Diego, CA, USA). Briefly, the MDA-MB-231 or MDA-MB-468 cells (6,500 cells/well; E-plate) were seeded into each well. Subsequently, the impedance of each well of the E-plate was measured continuously for 20-24 h at $37^{\circ} \mathrm{C}$ with $5 \% \mathrm{CO}_{2}$. For the cell proliferation assay, after the first 20-24 h, CTX or EGF was added to the wells and the impedance measurement was recorded for 72-96 h. For cellular morphology measurement, after the first 20-24 h, the medium in each well was replaced with serum-free medium and incubated for $4 \mathrm{~h}$ at $37^{\circ} \mathrm{C}$ with $5 \% \mathrm{CO}_{2}$. CTX or EGF was then added to the wells and impedance was recorded for $24 \mathrm{~h}$. The results were analysed using RTCA data analysis software 1.0 (ACEA Biosciences, Inc., San Diego, CA, USA).

Cell viability was also assessed by the WST-1 proliferation assay according to the manufacturer's instructions (Roche Applied Science, Mannheim, Germany).

Statistical analysis. Data are reported as the means \pm standard error of the mean, while ' $n$ ' represents the number of independent experiments for each indicated condition. The results were obtained from 4-5 independent experiments. Statistical analysis was performed using SPSS 17.0 software for Windows (SPSS, Inc., Chicago, IL, USA). Comparisons between multiple groups were performed with one-way analysis of variance followed by Tukey's post-hoc test. $\mathrm{P}<0.05$ was considered to indicate a statistically significant difference. 
A
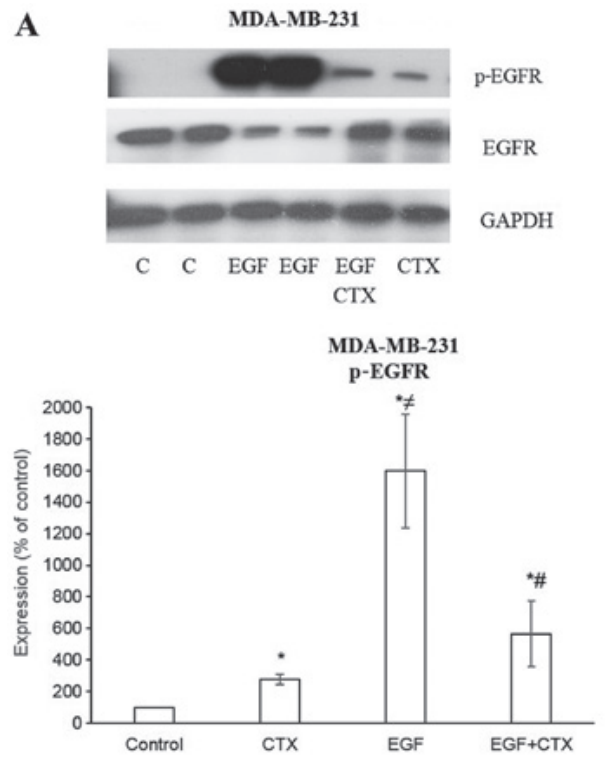

$\mathbf{B}$
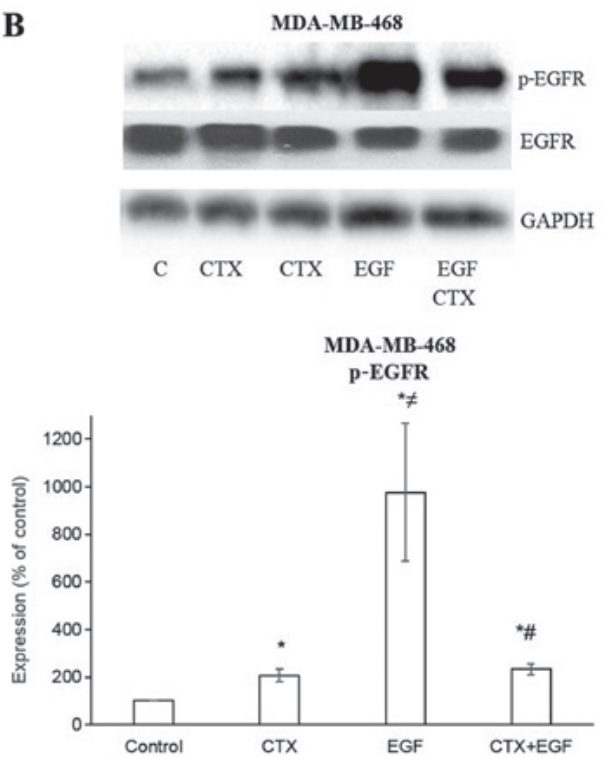

Figure 2. Cetuximab partially antagonizes the EGF-stimulated phosphorylation of EGFR. Cetuximab (100 nM, 30 min) produced significantly less EGFR phosphorylation than EGF (1 nM, $30 \mathrm{~min})$. Pre-treatment of the cells with CTX (100 nM, $30 \mathrm{~min})$ significantly, but not completely inhibited the EGF-induced phosphorylation (1 nM, $30 \mathrm{~min}$ ) of EGFR in (A) MDA-MB-231 and (B) MDA-MB-468. Representative western blot bands for p-EGFR and EGFR are presented along with two replicate bands for the control (indicated by ' $\mathrm{C}$ '), for the EGF treatment groups in (A), and for CTX in (B). Band intensities were normalized to GAPDH and presented as a percentage of phosphate buffered saline-treated control cells. Data are presented as the means \pm standard error of the mean, $\mathrm{n}=4-5$ experiments. ${ }^{*} \mathrm{P}<0.05$ vs. the control cells; ${ }^{\neq} \mathrm{P}<0.05$ vs. CTX; ${ }^{\mathrm{P}} \mathrm{P}<0.05$ vs. EGF. CTX, cetuximab; EGF, epidermal growth factor; EGFR, epidermal growth factor receptor.

A
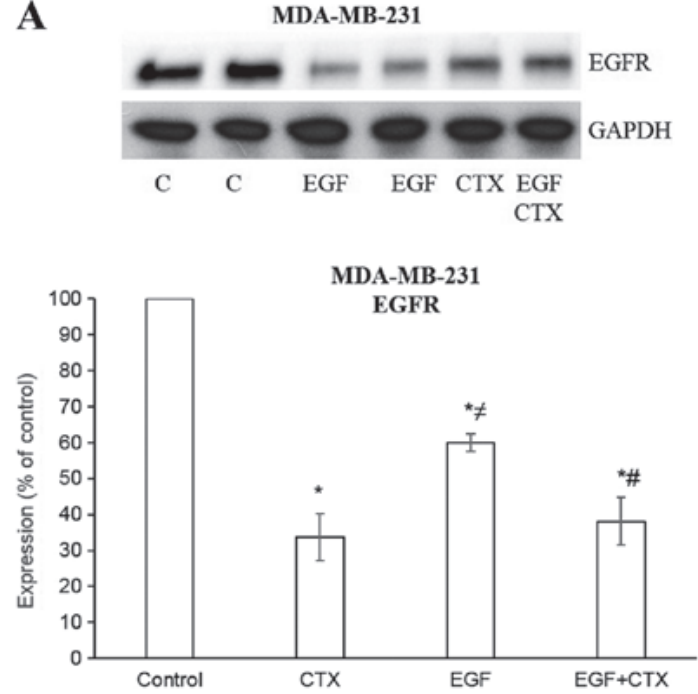

B
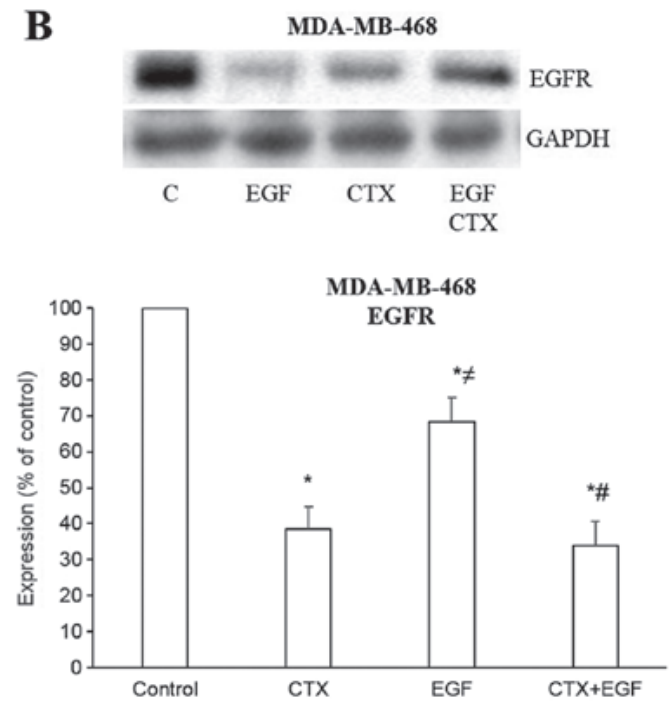

Figure 3. Cetuximab causes the degradation of EGFR. EGF (1 nM, 2 h) and CTX (100 nM, 2 h) both reduced the EGFR level, but CTX has a significantly less prominent effect on the EGFR level than EGF. Pre-treatment of the cells with CTX (100 nM, 30 min) significantly, but not completely inhibited the EGF-induced degradation (1 nM, 2 h) of EGFR in the (A) MDA-MB-231 and (B) MDA-MB-468 cells. Representative western blot bands for EGFR are presented. Two replicate bands are presented for the control (indicated as ' $\mathrm{C}$ ') and for the EGF treatment groups in (A). Band intensities are normalized to GAPDH and presented as a percentage of phosphate-buffered saline-treated control cells. Data are presented as the mean \pm standard error of the mean, $\mathrm{n}=4-5$ experiments. ${ }^{*} \mathrm{P}<0.05$ vs. the control cells; ${ }^{\neq} \mathrm{P}<0.05$ vs. CTX; ${ }^{\#} \mathrm{P}<0.05$ vs. EGF. CTX, cetuximab; EGF, epidermal growth factor; EGFR, epidermal growth factor receptor.

\section{Results}

CTX induces the phosphorylation of EGFR. The ligands that activate EGFR lead to the phosphorylation of the 1173 tyrosine residue of the EGFR receptor (5). CTX at concentrations of $0.01,0.1,1,10$ and $100 \mathrm{nM}$ significantly increased the phosphorylation of the 1173 tyrosine residue of the EGFR receptor (Fig. 1A), similar to EGF (Fig. 2A).
The CTX-stimulated phosphorylation was observable after $10 \mathrm{~min}$ of incubation at $100 \mathrm{nM}$ and persisted for $72 \mathrm{~h}$ in the MDA-MB-231 cells (Fig. 1C). CTX also induced EGFR phosphorylation in the MDA-MB-468 TNBC cells (Fig. 2B).

CTX induces less prominent EGFR phosphorylation compared with EGF. CTX at a concentration of $100 \mathrm{nM}$ [used as the maximum concentration, which is $>200$-fold its $\mathrm{Kd}$ 

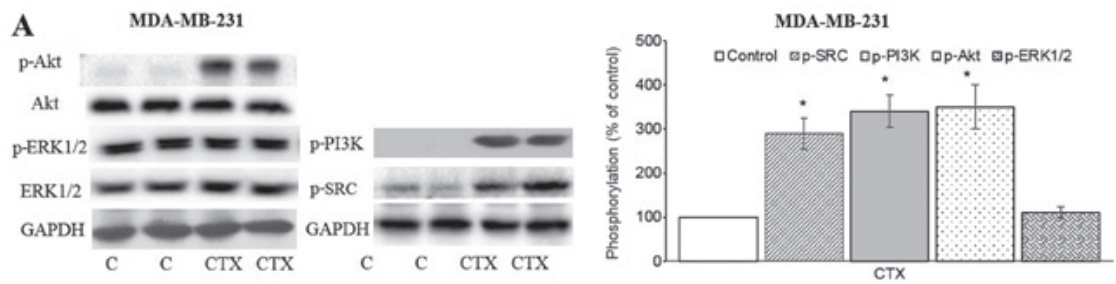

B

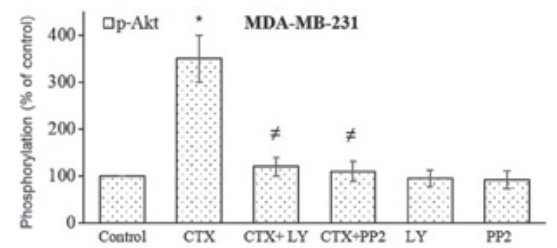

C
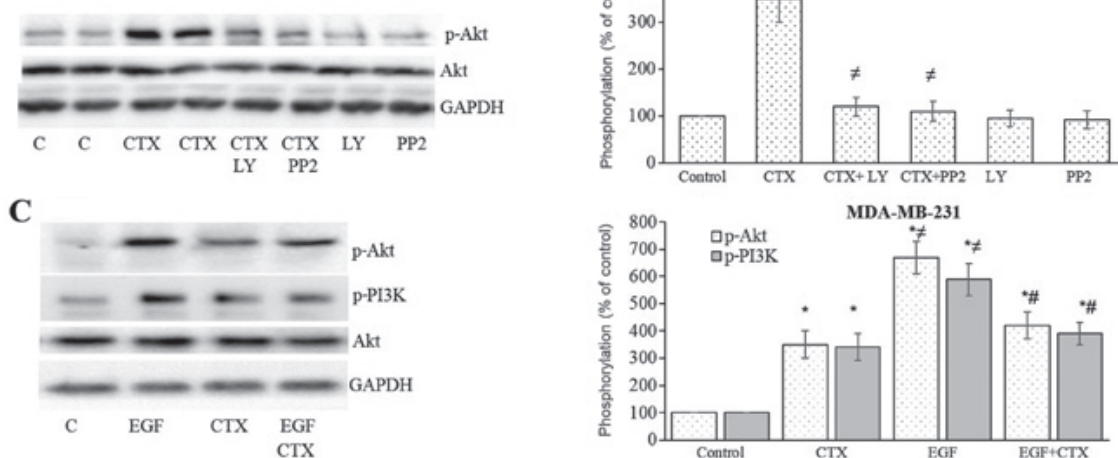

Figure 4. Cetuximab triggers the downstream signalling of EGFR in MDA-MB-231 cells. (A and B) Cetuximab (100 nM, 30 min) induced the phosphorylation of Src kinase, PI3K and Akt, but not that of ERK1/2 in the MDA-MB-231 cells. (B) Pre-treatment of cells with the PI3K inhibitor, LY294002 (10 $\mu$ M, 30 min), or the Src kinase inhibitor, PP2 (10 $\mu \mathrm{M}, 30 \mathrm{~min})$, significantly inhibited CTX-induced Akt phosphorylation. (C) CTX produced significantly less Akt or PI3K phosphorylation than EGF did, while pre-treatment of the cells with CTX (100 nM, $30 \mathrm{~min})$ significantly, but not completely inhibited the EGF-induced phosphorylation (1 nM, $30 \mathrm{~min}$ ) of PI3K and Akt in the MDA-MB-231 cells. Representative western blot bands for p-SRC, p-PI3K, p-Akt, p-ERK1/2, Akt and GADPH are presented. Two replicate bands are presented for the control or for the CTX treatment groups in (A and B). The p-Akt and p-ERK1/2 band intensities are normalized to Akt and ERK1/2, respectively, and the p-SRC and p-PI3K band intensities are normalized to GADPH and presented as a percentage of phosphate-buffered saline-treated control cells. Data are presented as the means \pm standard error of the mean, $n=4-5$ experiments. "P<0.05 vs. control cells; ${ }^{\ddagger} \mathrm{P}<0.05$ vs. CTX; ${ }^{\mathrm{P}}<0.05$ vs. EGF. CTX, cetuximab; EGF, epidermal growth factor; EGFR, epidermal growth factor receptor.

(dissociation constant) of $0.39 \mathrm{nM}$ and sufficient to saturate EGFR] produced significantly less EGFR phosphorylation compared with $1 \mathrm{nM}$ EGF, a full agonist, in both the MDA-MB-231 (Fig. 2A) and MDA-MB-468 (Fig. 2B) cells.

CTX partially inhibits EGF-mediated EGFR phosphorylation. It is well known that a partial agonist causes the incomplete inhibition of the response induced by a full agonist. Accordingly, CTX (100 nM) incompletely inhibited EGF-induced EGFR phosphorylation at the $1 \mathrm{nM}$ EGF concentration in both the MDA-MB-231 (Fig. 2A) and MDA-MB-468 (Fig. 2B) cells.

CTX causes the degradation of EGFR and partially inhibits the EGF-mediated degradation of EGFR. When measuring the EGFR levels following treatment of the cells with CTX (100 nM) or EGF (1 nM), a decreased level of EGFR was observed in the MDA-MB-231 (Figs. 1B and 3A) and MDA-MB-468 (Fig. 3B) cells. These results indicate that CTX functions like a partial agonist in the degradation of EGFR and, as expected, CTX reduces the EGFR levels to a lesser extent compared with EGF (Fig. 3). Furthermore, CTX only partially inhibited the EGF-mediated decrease in EGFR levels (Fig. 3).

CTX triggers the EGFR downstream pathway. After observing Tyr1173 phosphorylation of EGFR with CTX, the downstream signalling of EGFR was investigated.In the MDA-MB-231 cells, CTX treatment significantly enhanced the phosphorylation of Src kinase, PI3K and Akt, but not ERK1/2 (Fig. 4A and B). The phosphorylation of Akt was antagonized by the Src kinase inhibitor, PP2, and the PI3K inhibitor, LY294002 (Fig. 4B). It was therefore deduced that the stimulation of EGFR by CTX activates Src kinase and PI3K, and causes the phosphorylation of Akt. The CTX-mediated phosphorylation of PI3K and Akt was less prominent compared with that induced by EGF, and it also partially inhibited the EGF-stimulated phosphorylation of PI3K and Akt in the MDA-MB-231 cells (Fig. 4C).

In the MDA-MB-468 cells, CTX also increased the phosphorylation of Src kinase and PI3K, but not that of Akt and ERK1/2 (Fig. 5A). The CTX-mediated phosphorylation of PI3K was less prominent compared with that induced by EGF, and it also partially inhibited the EGF-stimulated phosphorylation of PI3K in the MDA-MB-468 cells (Fig. 5B). These results indicate that the partial agonistic activity of CTX is observable in the EGFR downstream signalling pathway.

The possible reasons as to why CTX did not increase the basal phosphorylation of ERK1/2 in the MDA-MB231 cells or the phosphorylation of ERK1/2 and Akt in the MDA-MB-468 cells are addressed below in the Discussion.

CTX induces IGF-1R and VEGFR-2 phosphorylation. In the present study, the effects of CTX or EGF on the phosphorylation status of IGF-1R and VEGFR-2 were also evaluated. CTX and EGF induced the phosphorylation of both IGF-1R and VEGFR-2 in the MDA-MB231 (Fig. 6) and MDA-MB-468 (Fig. 7) cells. This induced phosphorylation was inhibited by the EGFR tyrosine kinase inhibitor, AG1478, and the Src kinase inhibitor, PP2, in both the MDA-MB-231 (Fig. 6A and B) and MDA-MB-468 (Fig. 7A and B) cells. These results suggest that 


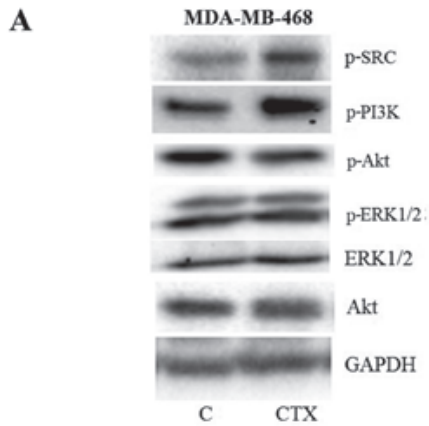

B

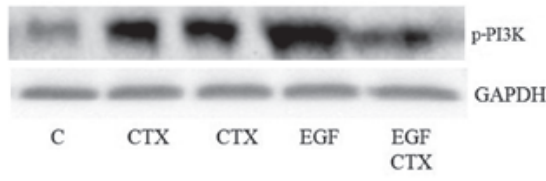

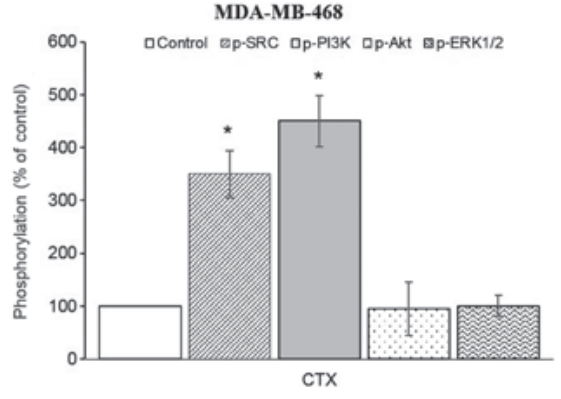

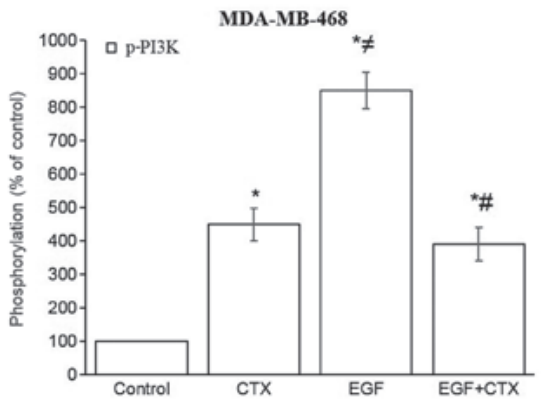

Figure 5. Cetuximab triggers the downstream signalling of EGFR in MDA-MB-468 cells. (A and B) Cetuximab (100 nM, 30 min) induced the phosphorylation of Src kinase and PI3K, but not that of Akt or ERK1/2 in MDA-MB-468 cells. (B) CTX produced significantly less PI3K-phosphorylation than EGF did, while pre-treatment of the cells with CTX (100 nM, $30 \mathrm{~min})$ significantly, but not completely inhibited the EGF-induced phosphorylation (1 nM, 30 min) of PI3K in MDA-MB-468 cells. Representative western blot bands for pSrc, pPI3K, pAkt, pERK1/2, Akt and GADPH are presented. Two replicate bands are presented for CTX in (B). The p-Akt and p-ERK1/2 band intensities are normalized to Akt and ERK1/2, respectively, and the p-Src, p-PI3K band intensities are normalized to GADPH and presented as a percentage of phosphate-buffered saline-treated control cells. Data are presented as the means \pm standard error of the mean, $\mathrm{n}=4-5$ experiments. ${ }^{*} \mathrm{P}<0.05$ vs. the control cells; ${ }^{*} \mathrm{P}<0.05$ vs. CTX; $\mathrm{P}<0.05$ vs. EGF. CTX, cetuximab; EGF, epidermal growth factor; EGFR, epidermal growth factor receptor.

$\mathbf{A}$
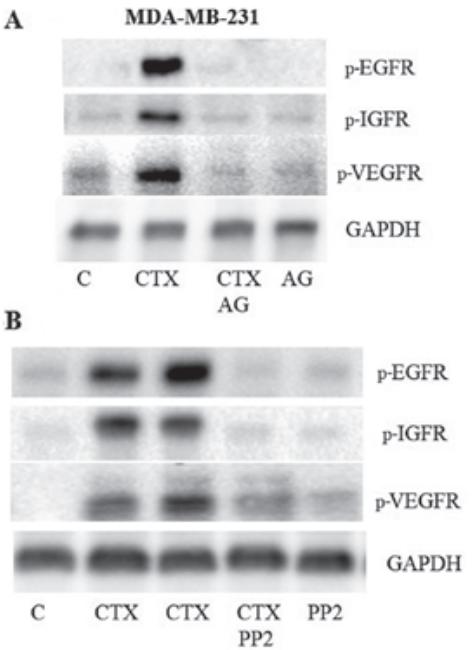

C

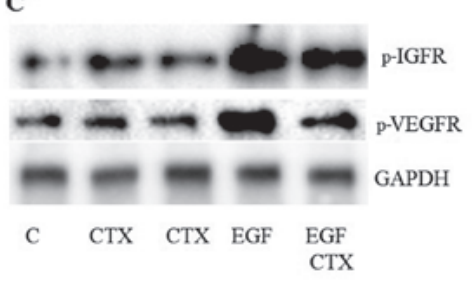

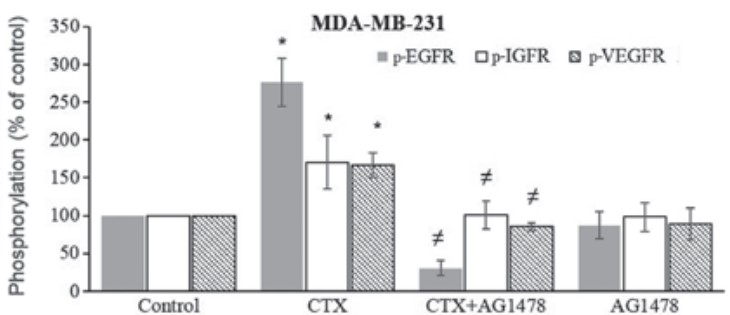
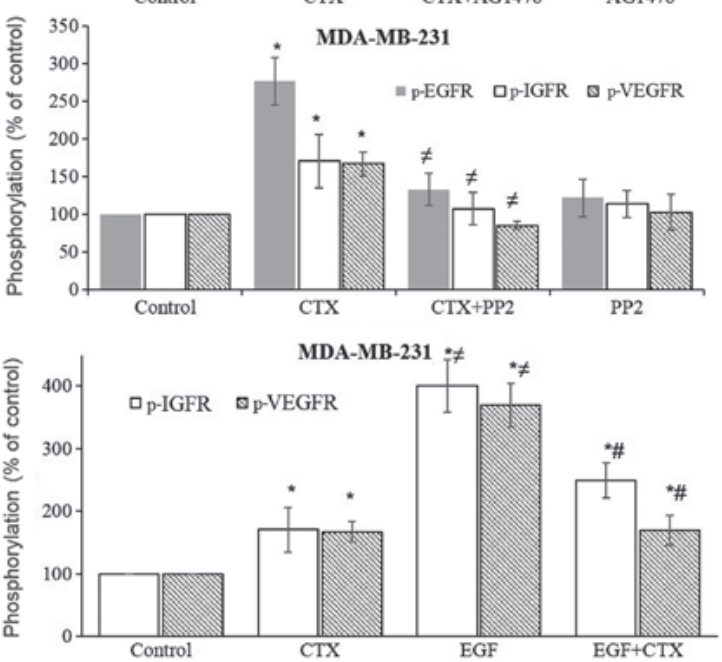

Figure 6. Cetuximab leads to the phosphorylation of IGF-1R and VEGFR-2 in MDA-MB-231 cells. (A and B) Cetuximab (100 nM, $30 \mathrm{~min})$ induced the phosphorylation of EGFR, IGF-1R and VEGFR-2, while pre-treatment of the cells with the EGFR tyrosine kinase inhibitor, AG1478 (10 $\mu$ M, 30 min), or the Src kinase inhibitor, PP2 (10 $\mu \mathrm{M}, 30 \mathrm{~min})$, significantly inhibited EGFR, IGF-1R and VEGFR-2 phosphorylation in MDA-MB-231 cells. (C) CTX produced significantly less IGF-1R and VEGFR-2-phosphorylation than EGF did, while pre-treatment of the cells with CTX (100 nM, $30 \mathrm{~min})$ significantly, but not completely inhibited EGF-induced phosphorylation (1 nM, $30 \mathrm{~min}$ ) of IGF-1R and VEGFR-2 in MDA-MB-231cells. Representative western blot bands for p-EGFR, p-IGF-1R, p-VEGFR-2 and GADPH are presented. Two replicate bands are presented for CTX in (B and C). The band intensities are normalized to GADPH and presented as a percentage of phosphate-buffered saline-treated control cells. Data are presented as the means \pm standard error of the mean, $\mathrm{n}=4-5$ experiments. " $\mathrm{P}<0.05$ vs. control cells; ${ }^{\neq} \mathrm{P}<0.05$ vs. CTX; "P<0.05 vs. EGF. CTX, cetuximab; EGF, epidermal growth factor; EGFR, epidermal growth factor receptor. 

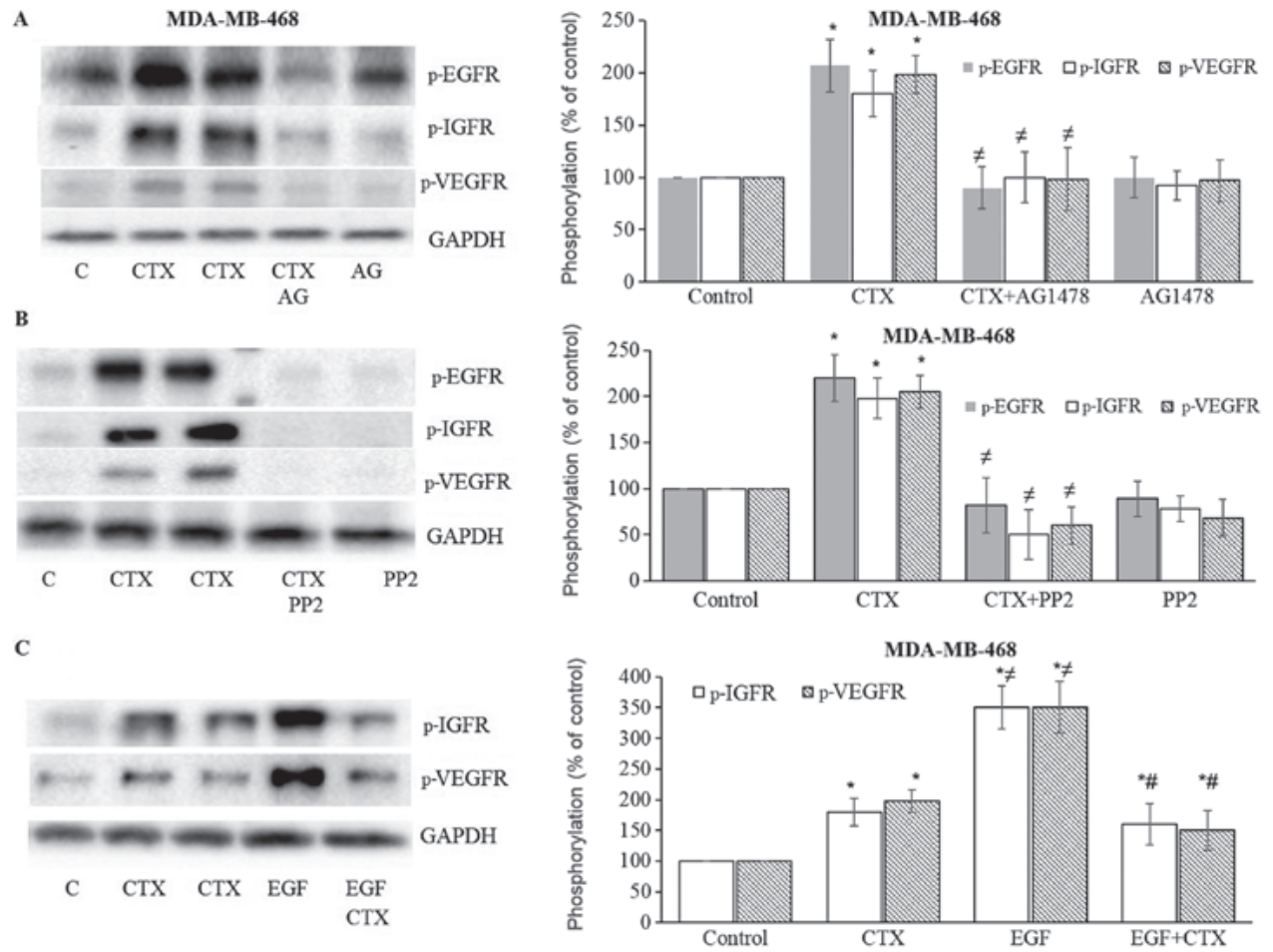

Figure 7. Cetuximab leads to the phosphorylation of IGF-1R and VEGFR-2 in MDA-MB-468 cells. (A and B) Cetuximab (100 nM, $30 \mathrm{~min})$ induced the phosphorylation of EGFR, IGF-1R, VEGFR-2, while pre-treatment of the cells with the EGFR tyrosine kinase inhibitor, AG1478 (AG) (10 $\mu$ M, $30 \mathrm{~min})$, or the Src inhibitor, PP2 (10 $\mu \mathrm{M}, 30 \mathrm{~min})$, significantly inhibited EGFR, IGF-1R and VEGFR-2 phosphorylation in MDA-MB-468 cells. (C) CTX produced significantly less IGF-1R and VEGFR-2 phosphorylation than EGF did, while pre-treatment of the cells with CTX (100 nM, 30 min) significantly but not completely inhibited the EGF-induced phosphorylation (1 nM, $30 \mathrm{~min}$ ) of IGF-1R and VEGFR-2 in MDA-MB-468 cells. Representative western blot bands for p-EGFR, p-IGF-1R, p-VEGFR-2 and GADPH are presented. Two replicate bands are presented for CTX. The band intensities are normalized to GADPH and presented as a percentage of phosphate-buffered saline-treated control cells. Data are presented as the means \pm standard error of the mean, $n=4-5$ experiments. ${ }^{*} \mathrm{P}<0.05$ vs. control cells; ${ }^{\circledR} \mathrm{P}<0.05$ vs. CTX; ${ }^{\mathrm{P}} \mathrm{P}<0.05$ vs. EGF. CTX, cetuximab; EGF, epidermal growth factor; EGFR, epidermal growth factor receptor.

the CTX-mediated activation of EGFR and Src kinase trigger the phosphorylation of IGF-1R and VEGFR-2.

CTX partially inhibits EGF-mediated IGF-1R and VEGFR-2 phosphorylation. As with EGFR phosphorylation, CTX treatment at $100 \mathrm{nM}$ produced significantly less IGF-1R and VEGFR-2 phosphorylation compared with the full agonist, EGF at $1 \mathrm{nM}$ (Figs. 6C and 7C). CTX also functioned as a partial agonist, partially inhibiting the IGF-1R and VEGFR-2 phosphorylation induced by EGF $(1 \mathrm{nM})$ in the MDA-MB-231 (Fig. 6C) and MDA-MB-468 cells (Fig. 7C).

CTX alters cellular morphology in a manner similar to $E G F$. Immediate morphological changes induced by growth factors can be detected using real-time cell-based impedance measurement (38-40). In this study, cell-based impedance technology was also used to evaluate the rapid morphological changes induced by RTK activity triggered by EGF or CTX in the MDA-MB-231 and MDA-MB-468 cells. Both CTX $(100 \mathrm{nM})$ and EGF $(1 \mathrm{nM})$ induced significant morphological changes during 4-10 h of cell stimulation (Fig. 8). These results indicate that CTX induces RTK activity similar to EGF in terms of cellular morphology in both the MDA-MB-231 and MDA-MB-468 cells.

Src kinase inhibitor enhances the CTX-mediated anti-proliferative effect. The effect of CTX on cellular proliferation was examined in the presence of the Src kinase inhibitor, PP2, which antagonizes the CTX-induced phosphorylation of Src kinase, PI3K, Akt, IGF-1R and VEGFR-2. CTX alone did not affect the proliferation of the MDA-MB-231 cells, but induced a $15 \%$ inhibition of the proliferation of the MDA-MB-468 cells (Fig. 9). The Src kinase inhibitor, PP2, at $10 \mu \mathrm{M}$ induced a 20 and 27\% inhibition of MDA-MB-231 and MDA-MB-468 cell proliferation, respectively. In combination with CTX, however, this response increased to 38\% in the MDA-MB-231 cells and to $45 \%$ in the MDA-MB-468 cells (Fig. 9). The results obtained by assessing cell viability by WST-1 assay (data not shown) and the RTCA system were similar.

Model of CTX-mediated partial agonistic action. Based on the observations that the CTX-mediated phosphorylation of EGFR, IGF-1R and VEGFR-2, PI3K and Akt were inhibited by the EGFR tyrosine kinase inhibitor, AG1478, and the Src kinase inhibitor, PP2, it was suggested that the partial agonistic action of CTX leads to the phosphorylation of EGFR and Src kinase, which mediates the phosphorylation of IGF-1R, VEGFR-2, PI3K and Akt (Fig. 10).

\section{Discussion}

The blocking and/or silencing of the EGFR signalling pathway is one of the fundamental treatment strategies for TNBC, since EGFR overexpression is associated with an aggressive phenotype and a poor clinical outcome (8-12). Several antibodies have been developed to shut down EGFR signalling 

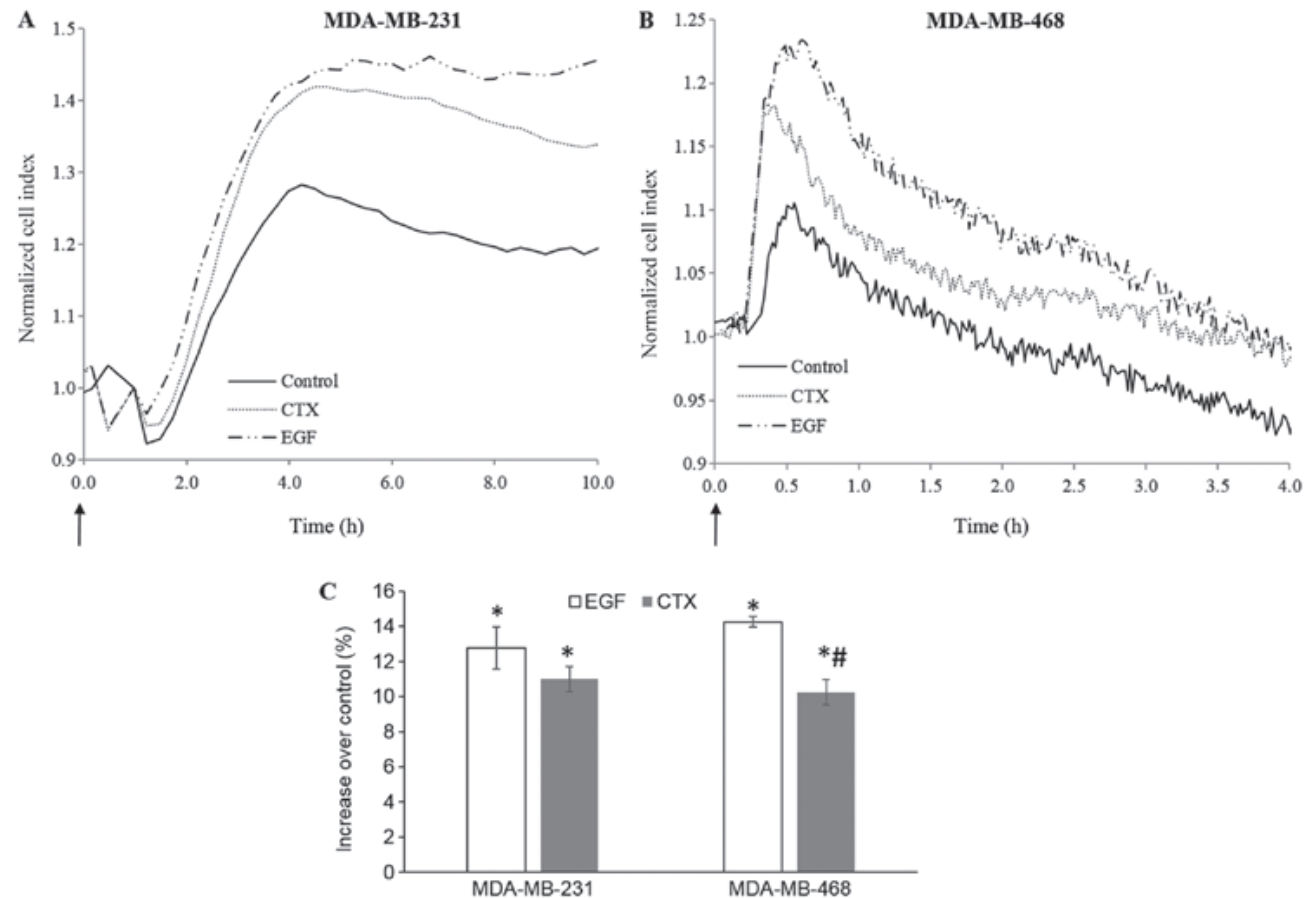

Figure 8. Cetuximab and EGF alter cell morphology. (A-C) Impedance measurement of cell morphology with the real-time cell electronic sensing system with cetuximab (100 nM) or EGF (1 nM) treatment in serum-free medium in MDA-MB-231 and MDA-MB-468 cells. CTX and EGF produced significant increase in the cell index. The cell index recorded just before CTX or EGF treatment was defined as the baseline and fold change of the baseline was determined for further measurements and shown as cell index fold change in (A and B). The peak level of cell index fold change was defined as the maximum value reached after treatment. The percentage of phosphate-buffered saline-treated control cells at the peak level was calculated and percentage increase over control cells was presented as a bar graph in $(\mathrm{C})$. The arrows indicate when the treatments were started. Data are presented as the means \pm standard error of the mean, $\mathrm{n}=4-5$ experiments. ${ }^{*} \mathrm{P}<0.05$ vs. the control cells; ${ }^{*} \mathrm{P}<0.05$ vs. EGF. CTX, cetuximab; EGF, epidermal growth factor; EGFR, epidermal growth factor receptor.
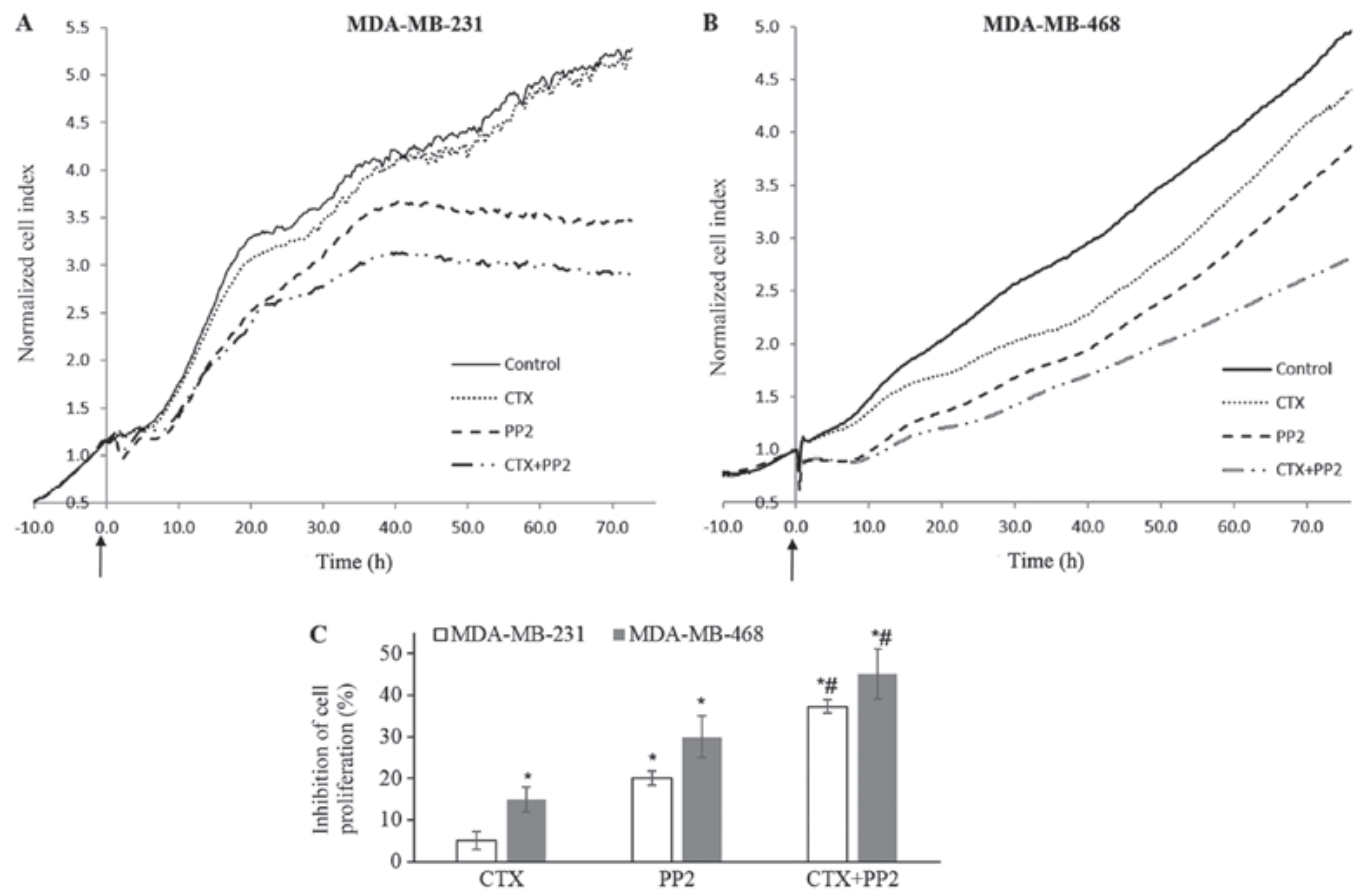

Figure 9. Src kinase inhibition enhances the cetuximab-mediated anti-proliferative response. (A-C) Impedance measurement of cell proliferation with the real-time cell electronic sensing system with cetuximab $(100 \mathrm{nM}), \mathrm{PP} 2(10 \mu \mathrm{M})$ and CTX $(100 \mathrm{nM})+\mathrm{PP} 2(10 \mu \mathrm{M})$ treatment of MDA-MB-231 and MDA-MB-468 cells in medium with FBS (10\%). CTX alone did not alter the proliferation of MDA-MB-231 cells, but it induced a 15\% inhibition of the proliferation of MDA-MB-468 cells. The Src kinase inhibitor, PP2, at $10 \mu \mathrm{M}$ induced $20 \%$ and $27 \%$ inhibition of cellular proliferation. This response significantly increased to reach $38 \%$ and $45 \%$ when combined with CTX in MDA-MB-231 and MDA-MB-468 cells, respectively. The cell index recorded just before CTX, PP2 or CTX+PP2 treatment was defined as the baseline and fold change of the baseline was determined for further measurements and shown as cell index fold change in (A and B). The arrows indicate when the treatments were started. The cell index fold change at $72 \mathrm{~h}$ for each group and the percentage of phosphate-buffered saline-treated control cells was determined and percent inhibition of the cell index obtained from phosphate buffered saline-treated control cells was presented as a bar graph in (C). Data are presented as the means \pm standard error of the mean, $n=4-5$ experiments. " $\mathrm{P}<0.05$ vs. the control cells; ${ }^{\#} \mathrm{P}<0.05$ vs. EGF. CTX, cetuximab; EGF, epidermal growth factor; EGFR, epidermal growth factor receptor. 


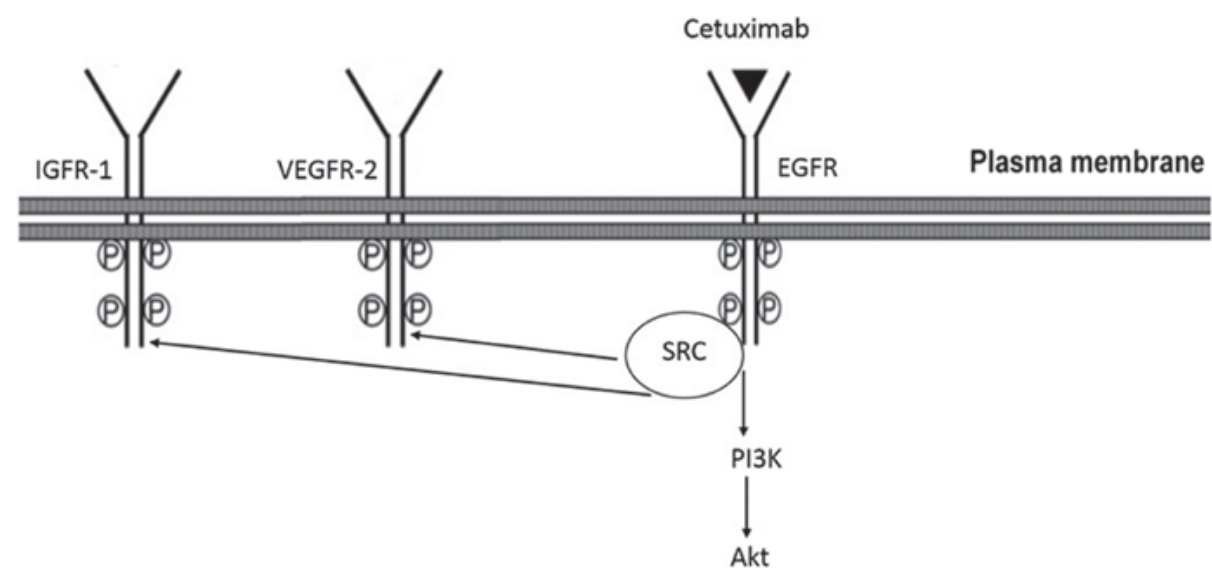

Figure 10. Model of cetuximab effect on epidermal growth factor receptor (EGFR) in breast cancer cell lines. Cetuximab leads to transactivation of IGF-1R and VEGFR-2 via an EGFR and Src kinase-dependent pathway in MDA-MB-231 and MDA-MB-468 cells, which also causes activation of phosphoinositide-3-kinase (PI3K) in both cell lines and serine-threonine kinases (Akt) in MDA-MB-231 cells.

by blocking the binding of growth factors. However, these antibodies may not only antagonize the binding of growth factors or completely shut down EGFR signalling, but may also exert agonist-like effects or act like partial agonists (24-26). One of the unavoidable results of this action may be triggering malignant signalling in cancer cells, similar to growth factors, which may explain the lack of an anticancer response pattern in TNBC cells. TNBCs are resistant to treatment with the EGFR antibody, CTX. The primary focus of the present study was to determine whether CTX possesses partial agonist-like properties and triggers the EGFR signalling pathway; we then investigated whether these properties are partly responsible for TNBC cell resistance to CTX.

To define an antibody as a partial agonist, it must exert an agonistic effect upon binding to a receptor. To elucidate this, we initially determined whether CTX causes the auto-phosphorylation of EGFR and triggers its downstream signalling pathway similar to an EGFR agonist. It was observed that the treatment of MDA-MB-231 and MDA-MB-468 cells with CTX significantly increased the Tyr1173 phosphorylation of EGFR, which was the first indication that CTX may function as a partial agonist of EGFR. To determine whether the CTX-mediated Tyr1173 phosphorylation of EGFR triggers downstream signalling, the activity status of Src kinase, PI3K, Akt and ERK1/2 in the CTX-treated cells was then evaluated. CTX treatment was found to markedly enhance the phosphorylation of Src kinase, PI3K and Akt in the MDA-MB-231 cells, and the phosphorylation of Src kinase and PI3K in the MDA-M468 cells. However, we observed no increase in the phosphorylation of ERK1/2 with CTX treatment in either the MDA-MB-231 or MDA-MB-468 cells. This may be explained by the high level of ERK1/2 expression in these cells, together with the high basal phosphorylated ERK1/2 level (41), which may also be linked to KRAS and BRAF mutations in MDA-MB-231 cells (21). Therefore, CTX cannot further promote the phosphorylation of ERK1/2 in these cell lines. Similarly, CTX did not enhance Akt phosphorylation in MDA-MB-468 cells, which is also most likely associated with the high basal level of phosphorylated Akt in MDA-MB-468 cells, which lack the functional tumour suppressor Akt-inhibiting gene, PTEN $(21,42)$. By contrast, EGF, as a full agonist, did enhance ERK1/2 and Akt phosphorylation in these cell lines (data not shown). These results indicate that the signal strength must be at the level induced by the full agonist (EGF) on EGFR in order to observe Akt or ERK1/2 phosphorylation, whereas the weak signal induced by the partial agonist (CTX), is not sufficient to achieve phosphorylation of ERK1/2 and Akt in the MDA-MB-468 and ERK1/2 in MDA-MB-231 cells.

Growth factors cause the activation of both their own specific receptors and different types of growth factor receptors $(34,35)$. The EGF stimulation of EGFR leads to the phosphorylation of IGF-1R in an Src kinase-dependent manner (34). There is also a synergistic interaction between EGFR and VEGFR-2, while EGF stimulation increases both the expression and phosphorylation of VEGFR-2 (35), and activation of Src kinase also mediates transactivation of VEGFR-2 (43). After observing the CTX-mediated phosphorylation of EGFR and Src kinase, the effect of CTX on IGF-1R and VEGFR-2 phosphorylation was examined, and it was observed that CTX enhanced the phosphorylation of both, and that this induced phosphorylation was inhibited by the EGFR tyrosine kinase inhibitor, AG1478, and the Src kinase inhibitor, PP2. In our experiments, although CTX treatment led to an increase in the level of phosphorylated IGF-1R and VEGFR-2, it caused some decline or no change in the level of IGR-1 and VEGF-2. After observing this variability in the total level of IGF-1R or VEGF-2 we did not measure their level in each experiment. The stimulation or phosphorylation of tyrosine kinase residues of EGFR, VEGFR-2 and IGF-1R leads to their internalization and degradation but does not increase their cellular level (44-47). We also observed that CTX stimulation significantly decreased the level of EGFR (Figs. 1-3). Taken together, our data suggest that the CTX-mediated phosphorylation of EGFR, VEGFR-2 and IGF-1R is not related to an increase in their expression level. Based on these findings, it is suggested that the CTX-mediated activation of EGFR tyrosine kinase leads to the phosphorylation of EGFR and triggers Src kinase activation, which mediates the phosphorylation of IGF-1R and VEGFR-2 (Fig. 10).

As mentioned above, the stimulation of EGFR by agonists, such as EGF, causes the rapid internalization and degradation of the receptor (44). Based on these and our initial observations 
indicating the decline in the level of EGFR with both CTX and EGF treatments, we measured the EGFR levels following treatment with CTX to further evaluate the agonist-like action of CTX. It was observed that CTX treatment led to a decline in EGFR levels in both the MDA-MB-231 and MDA-MB468 cells. In this response pattern, CTX acted as an agonist, but did not reduce the EGFR levels to a greater extent than EGF. Riese (26) proposed that partial agonist/antagonist antibodies trigger the phosphorylation of the Tyr residues of RTKs, leading to the degradation and irreversible inhibition of the receptor. This partial agonistic property of monoclonal antibodies may be an advantage for EGFR-targeted anticancer effectiveness. Ferraro et al (48) also suggested an alternative strategy for inhibiting tumour growth by enhancing the internalization of EGFR, increasing its degradation and inhibiting its recycling through the use of EGFR-targeted monoclonal antibodies. From our results, it may be concluded that although CTX causes the degradation of EGFR, this is not sufficient to exert a pronounced anti-proliferative effect on TNBC cells.

Several studies have demonstrated that growth factors and RTK agonists induce immediate morphological or behavioural changes that may be detected using real-time cell-based impedance measurement (38-40). Thus, in this study, we also measured the effect of CTX on cellular behaviour or morphology as another approach to evaluating its partial agonist-like activity. CTX was found to induce significant morphological changes in the cells, similar to EGF, indicating that CTX has a partial agonistic action in terms of cellular morphology. It would also be better to visualize the morphological changes induced with CTX in these cells by using microscopic techniques in a future study.

The second important indication to define an antibody as a partial agonist is that it has a notably lower signal strength compared with a full agonist. We therefore compared CTX- and EGF-mediated responses. All the responses induced by CTX, namely the phosphorylation of EGFR, IGF-1R, VEGFR-2, Akt and PI3K, and reduced EGFR levels, were significantly less pronounced compared with those induced by EGF as a full agonist. These results clearly indicate that CTX can partially, but not fully, activate EGFR. A third typical indication of a partial agonist is that it partially inhibits the response induced by a full agonist. Our results clearly demonstrated that CTX partially, but not fully, inhibited the EGF-mediated responses.

An important aspect of the results of the present study is that the partial agonistic action of CTX causes EGFR phosphorylation on the Tyr1173 residue, leading to the phosphorylation of Src kinase, PI3K, Akt, IGF-1R and VEGFR-2. All these signalling molecules are coupled to a malignant phenotype. Previous research, as well as the present study, have demonstrated that MDA-MB-231 and MDA-MB-468 cells are resistant to CTX treatment $(33,49,50)$. This partial agonistic property may therefore be implicated in the mechanism underlying the resistance of these cell lines to CTX. Based on the observation that the inhibition of Src kinase significantly inhibited the CTX-mediated phosphorylation of PI3K, Akt, IGF-1R and VEGFR-2, we investigated whether the activation of Src kinase could partly explain the resistance of these cells to CTX. For this purpose, the effect of CTX on cellular proliferation was examined in the presence of the Src kinase inhibitor, PP2, in the MDA-MB-231 and MDA-MB-468 cells. Indeed, PP2 significantly enhanced the CTX-mediated anti-proliferative response in these cell lines. As expected, however, the partial agonistic action of CTX could not fully explain the resistance observed in these cell lines, since these cells harbour mutations in KRAS/BRAF and PTEN that cause EGFR-independent activation of malignant signalling.

Various results reported in the literature also support our findings that CTX can cause the phosphorylation of EGFR, IGF-1R and Src kinase in several different cancer cell lines, which are primarily refractory or have acquired resistance $(30-32,51,52)$. In particular, CTX-sensitive cancer cells may become resistant following CTX treatment (18,53-55). There is evidence to indicate that EGFR, HER2, HER3, c-Met and VEGFR-2 are overexpressed, and also that Src kinase and PI3K/Akt activity increase in acquired CTX resistance (18-20,54,56-58). CTX can phosphorylate and activate EGFR in non-small cell lung cancer cells or in head and neck squamous cancer cells $(30,31,54)$. Yoshida et al (30) reported that CTX led to the dimerization of EGFR and caused the phosphorylation of the Tyr845, Tyr1068 and Tyr1173 residues in the non-small cell lung cancer cells lines, H292 and H460. Accordingly, it is very important to examine and elucidate a possible partial agonist action of CTX and its role in acquired resistance of cancer cells. The CTX-mediated phosphorylation or activation of growth factor receptors have not been specifically addressed to date as a mechanism underlying resistance, and this phenomenon has not been defined as partial agonism. The results of the present study are novel, as they clearly demonstrated the partial agonist action of CTX and, therefore, have drawn attention to the possibility that the partial agonistic action of monoclonal antibodies may be key to the resistance to EGFR-targeted therapies.

To further elucidate the effectiveness of EGFR-targeted antibodies in cancer cells exhibiting high EGFR signalling, it would be valuable to compare the anticancer effectiveness of antibodies with different properties or efficacies; one may act like a neutral antagonist on EGFR, thereby preventing any type of phosphorylation or activation of EGFR or its downstream signalling molecules, whereas another may act like a biased agonist that selectively triggers a specific EGFR signalling pathway. The binding of this type of antibody to EGFR may lead to the phosphorylation of the Tyr residues that trigger its ubiquitination and facilitate its degradation, but without the phosphorylation of the Tyr residues that trigger malignant signalling. Such an antibody could completely shut down EGFR signalling. Therefore, it is crucial to understand the therapeutic effectiveness of EGFR-targeted antibodies with different properties, such as partial agonists, neutral antagonists and biased agonists, in the treatment of cancers that retain high EGFR signalling.

In conclusion, the results of the present study indicate that CTX exerts a partial agonistic effect on EGFR, which leads to the phosphorylation of EGFR, Src kinase, PI3K, Akt, IGF-1R and VEGFR-2, whereas the inhibition of this induced phosphorylation by the Src kinase inhibitor, PP2, enhances its anti-proliferative effect. To the best of our knowledge, this study is the first to emphasize the partial agonist properties of CTX, which are likely implicated in the mechanisms underlying the resistance of MDA-MB231 and MDA-MB468 cells to CTX. The anticancer effectiveness of 
CTX should thus be examined further by blocking its partial agonist action through Src kinase inhibition in preclinical and clinical studies.

\section{Acknowledgements}

The authors would like to thank Dr Bala Gur Dedeoğlu (Biotechnology Institute, University of Ankara, Ankara, Turkey) for her critical reading of the manuscript.

\section{Funding}

The present study was supported by a research grant from the Scientific and Technological Research Council of Turkey (TÜBITAK; grant no. SBAG-113S396).

\section{Availability of data and materials}

All data generated or analysed during this study are included in this published article or are available from the corresponding author on reasonable request.

\section{Authors' contributions}

HG, MMT and SYB participated in the design of the study. MMT, SYB and BD performed the experiments and generated the data. HG, MMT, SYB and BD analysed and reviewed the Results and Discussion. HG and SYB prepared the manuscript and revised it. All authors have read and approved the final version of the manuscript.

\section{Ethics approval and consent to participate}

Not applicable.

\section{Patient consent for publication}

Not applicable.

\section{Competing interests}

The authors declare that they have no competing interests.

\section{References}

1. Lewis TS, Shapiro PS and Ahn NG: Signal transduction through MAP kinase cascades. Adv Cancer Res 74: 49-139, 1998.

2. Klapper LN, Kirschbaum MH, Sela M and Yarden Y: Biochemical and clinical implications of the ErbB/HER signaling network of growth factor receptors. Adv Cancer Res 77: 25-79, 2000

3. Vivanco I and Sawyers CL: The phosphatidylinositol 3-Kinase AKT pathway in human cancer. Nat Rev Cancer 2: 489-501, 2002.

4. Chong CR and Jänne PA: The quest to overcome resistance to EGFR-targeted therapies in cancer. Nat Med 19: 1389-1400, 2013.

5. Downward J, Parker P and Waterfield MD: Autophosphorylation sites on the epidermal growth factor receptor. Nature 311: 483-485, 1984

6. Brenton JD, Carey LA, Ahmed AA and Caldas C: Molecular classification and molecular forecasting of breast cancer: Ready for clinical application? J Clin Oncol 23: 7350-7360, 2005.

7. Hurvitz $S$ and Mead M: Triple-negative breast cancer: advancements in characterization and treatment approach. Curr Opin Obstet Gynecol 28: 59-69, 2016.
8. DiGiovanna MP, Stern DF, Edgerton SM, Whalen SG, Moore D II and Thor AD: Relationship of epidermal growth factor receptor expression to ErbB-2 signaling activity and prognosis in breast cancer patients. J Clin Oncol 23: 1152-1160, 2005.

9. Bhargava R, Gerald WL, Li AR, Pan Q, Lal P, Ladanyi M and Chen B: EGFR gene amplification in breast cancer: Correlation with epidermal growth factor receptor mRNA and protein expression and HER-2 status and absence of EGFR-activating mutations. Mod Pathol 18: 1027-1033, 2005.

10. Rimawi MF, Shetty PB, Weiss HL, Schiff R, Osborne CK, Chamness GC and Elledge RM: Epidermal growth factor receptor expression in breast cancer association with biologic phenotype and clinical outcomes. Cancer 116: 1234-1242, 2010.

11. Burness ML, Grushko TA and Olopade OI: Epidermal growth factor receptor in triple-negative and basal-like breast cancer: Promising clinical target or only a marker? Cancer J 16: 23-32, 2010.

12. Nielsen TO, Hsu FD, Jensen K, Cheang M, Karaca G, Hu Z, Hernandez-Boussard T, Livasy C, Cowan D, Dressler L, et al: Immunohistochemical and clinical characterization of the basal-like subtype of invasive breast carcinoma. Clin Cancer Res 10: 5367-5374, 2004.

13. Sunada H, Magun BE, Mendelsohn J and MacLeod CL: Monoclonal antibody against epidermal growth factor receptor is internalized without stimulating receptor phosphorylation. Proc Natl Acad Sci USA 83: 3825-3829, 1986.

14. Vincenzi B, Zoccoli A, Pantano F, Venditti O and Galluzzo S: Cetuximab: From bench to bedside. Curr Cancer Drug Targets 10: 80-95, 2010.

15. Kawamoto T, Sato JD, Le A, Polikoff J, Sato GH and Mendelsohn J: Growth stimulation of A431 cells by epidermal growth factor: Identification of high-affinity receptors for epidermal growth factor by an anti-receptor monoclonal antibody. Proc Natl Acad Sci USA 80: 1337-1341, 1983.

16. Ciardiello F and Tortora G: EGFR antagonists in cancer treatment. N Engl J Med 358: 1160-1174, 2008.

17. Carey LA, Rugo HS, Marcom PK, Mayer EL, Esteva FJ, Ma CX, Liu MC, Storniolo AM, Rimawi MF, Forero-Torres A, et al: TBCRC 001: Randomized phase II study of cetuximab in combination with carboplatin in stage IV triple-negative breast cancer. J Clin Oncol 30: 2615-2623, 2012.

18. Brand TM, Iida M and Wheeler DL: Molecular mechanisms of resistance to the EGFR monoclonal antibody cetuximab. Cancer Biol Ther 11: 777-792, 2011

19. Bardelli A and Siena S: Molecular mechanisms of resistance to cetuximab and panitumumab in colorectal cancer. J Clin Oncol 28: 1254-1261, 2010.

20. Sforza V, Martinelli E, Ciardiello F, Gambardella V, Napolitano S, Martini G, Della Corte C, Cardone C, Ferrara ML, Reginelli A, et al: Mechanisms of resistance to anti-epidermal growth factor receptor inhibitors in metastatic colorectal cancer. World J Gastroenterol 22: 6345-6361, 2016.

21. Hollestelle A, Elstrodt F, Nagel JHA, Kallemeijn WW and Schutte M: Phosphatidylinositol-3-OH kinase or RAS pathway mutations in human breast cancer cell lines. Mol Cancer Res 5: 195-201, 2007.

22. Hsu HC, Thiam TK, Lu YJ, Yeh CY, Tsai WS, You JF, Hung HY, Tsai CN, Hsu A, Chen HC, et al: Mutations of KRAS/NRAS/BRAF predict cetuximab resistance in metastatic colorectal cancer patients. Oncotarget 7: 22257-22270, 2016.

23. Macdonald-Obermann JL and Pike LJ: Different epidermal growth factor (EGF) receptor ligands show distinct kinetics and biased or partial agonism for homodimer and heterodimer formation. J Biol Chem 289: 26178-26188, 2014.

24. Prat M, Oltolina F and Basilico C: Monoclonal Antibodies against the MET/HGF Receptor and Its Ligand: Multitask Tools with Applications from Basic Research to Therapy. Biomedicines 2: 359-383, 2014.

25. Deb TB, Zuo AH, Barndt RJ, Sengupta S, Jankovic R and Johnson MD: Pnck overexpression in HER-2 gene-amplified breast cancer causes Trastuzumab resistance through a paradoxical PTEN-mediated process. Breast Cancer Res Treat 150: 347-361, 2015.

26. Riese DJ II: Ligand-based receptor tyrosine kinase partial agonists: New paradigm for cancer drug discovery? Expert Opin Drug Discov 6: 185-193, 2011.

27. Scott GK, Dodson JM, Montgomery PA, Johnson RM, Sarup JC, Wong WL, Ullrich A, Shepard HM and Benz CC: p185HER2 signal transduction in breast cancer cells. J Biol Chem 266: 14300-14305, 1991. 
28. Nagata Y, Lan K-H, Zhou X, Tan M, Esteva FJ, Sahin AA, Klos KS, Li P, Monia BP, Nguyen NT, et al: PTEN activation contributes to tumor inhibition by trastuzumab, and loss of PTEN predicts trastuzumab resistance in patients. Cancer Cell 6: $117-127,2004$

29. Esteva FJ, Yu D, Hung M-C and Hortobagyi GN: Molecular predictors of response to trastuzumab and lapatinib in breast cancer. Nat Rev Clin Oncol 7: 98-107, 2010

30. Yoshida T, Okamoto I, Okabe T, Iwasa T, Satoh T, Nishio K, Fukuoka $M$ and Nakagawa K: Matuzumab and cetuximab activate the epidermal growth factor receptor but fail to trigger downstream signaling by Akt or Erk. Int J Cancer 122: 1530-1538, 2008.

31. Raben D, Helfrich B, Chan DC, Ciardiello F, Zhao L, Franklin W, Barón AE, Zeng C, Johnson TK and Bunn PA Jr: The effects of cetuximab alone and in combination with radiation and/or chemotherapy in lung cancer. Clin Cancer Res 11: 795-805, 2005

32. MolliPR, Adam L and Kumar R: Therapeutic IMC-C225 antibody inhibits breast cancer cell invasiveness via Vav2-dependent activation of RhoA GTPase. Clin Cancer Res 14: 6161-6170, 2008.

33. El Guerrab A, Bamdad M, Bignon YJ, Penault-Llorca F and Aubel C: Anti-EGFR monoclonal antibodies enhance sensitivity to DNA-damaging agents in BRCA1-mutated and PTEN-wild-type triple-negative breast cancer cells. Mol Carcinog 56: 1383-1394, 2017.

34. Hallak H, Moehren G, Tang J, Kaou M, Addas M, Hoek JB and Rubin R: Epidermal growth factor-induced activation of the insulin-like growth factor I receptor in rat hepatocytes. Hepatology 36: 1509-1518, 2002.

35. Saryeddine L, Zibara K, Kassem N, Badran B and El-Zein N: EGF-Induced VEGF Exerts a PI3K-Dependent Positive Feedback on ERK and AKT through VEGFR2 in Hematological In Vitro Models. PLoS One 11: e0165876, 2016.

36. Tuglu MM, Bostanabad SY, Ozyon G, Dalkiliç B and Gurdal H: The role of dual specificity phosphatase 1 and protein phosphatase 1 in $\beta_{2}$ adrenergic receptor mediated inhibition of extracellular signal regulated kinase $1 / 2$ in triple negative breast cancer cell lines. Mol Med Rep 17: 2033-2043, 2018.

37. Solly K, Wang X, Xu X, Strulovici B and Zheng W: Application of real-time cell electronic sensing (RT-CES) technology to cell-based assays. Assay Drug Dev Technol 2: 363-372, 2004.

38. Atienza JM, Yu N, Wang X, Xu X and Abassi Y: Label-free and real-time cell-based kinase assay for screening selective and potent receptor tyrosine kinase inhibitors using microelectronic sensor array. J Biomol Screen 11: 634-643, 2006.

39. Dynamic Monitoring of Receptor Tyrosine Kinase Activation in Living Cells Dynamic Monitoring of Receptor Tyrosine Kinase Activation in Living Cells. ACEA Biosciences, Inc., San Diego, CA, 2013

40. Chinkers M, McKanna JA and Cohen S: Rapid induction of morphological changes in human carcinoma cells A-431 by epidermal growth factors. J Cell Biol 83: 260-265, 1979.

41. Bartholomeusz C, Gonzalez-Angulo AM, Liu P, Hayashi N, Lluch A, Ferrer-Lozano J and Hortobágyi GN: High ERK protein expression levels correlate with shorter survival in triple-negative breast cancer patients. Oncologist 17: 766-774, 2012.

42. Stemke-hale K, Gonzalez-Angulo AM, Lluch A, Neve RM, Kuo WL, Davies M, Carey M, Hu Z, Guan Y, Sahin A, et al: An integrative genomic and proteomic analysis of PIK3CA, PTEN, and AKT mutations in breast cancer. Cancer Res 68: 6084-6092, 2008.

43. Petreaca ML, Yao M, Liu Y, Defea K and Martins-Green M: Transactivation of vascular endothelial growth factor receptor-2 by interleukin-8 (IL-8/CXCL8) is required for IL-8/CXCL8-induced endothelial permeability. Mol Biol Cell 18 5014-5023, 2007.
44. Vieira AV, Lamaze C and Schmid SL: Control of EGF receptor signaling by clathrin-mediated endocytosis. Science 274: 2086-2089, 1996.

45. Carpentier JL: Insulin receptor internalization: Molecular mechanisms and physiopathological implications. Diabetologia 37 (Suppl 2): S117-S124, 1994.

46. Bruns AF, Herbert SP, Odell AF, Jopling HM, Hooper NM, Zachary IC, Walker JH and Ponnambalam S: Ligand-stimulated VEGFR2 signaling is regulated by co-ordinated trafficking and proteolysis. Traffic 11: 161-174, 2010.

47. Chow JC, Condorelli G and Smith RJ: Insulin-like growth factor-I receptor internalization regulates signaling via the Shc/mitogen-activated protein kinase pathway, but not the insulin receptor substrate-1 pathway. J Biol Chem 273: 4672-4680, 1998.

48. Ferraro DA, Gaborit N, Maron R, Cohen-Dvashi H, Porat Z, Pareja F, Lavi S, Lindzen M, Ben-Chetrit N, Sela M, et al: Inhibition of triple-negative breast cancer models by combinations of antibodies to EGFR. Proc Natl Acad Sci USA 110 $1815-1820,2013$

49. El Guerrab A, Bamdad M, Kwiatkowski F, Bignon YJ, Penault-Llorca F and Aubel C: Anti-EGFR monoclonal antibodies and EGFR tyrosine kinase inhibitors as combination therapy for triple-negative breast cancer. Oncotarget 7: 73618-73637, 2016.

50. Sohn J, Liu S, Parinyanitikul N, Lee J, Hortobagyi GN, Mills GB, Ueno NT and Gonzalez-Angulo AM: cMET activation and EGFR-directed therapy resistance in triple-negative breast cancer. J Cancer 5: 745-753, 2014.

51. Li X, Xu L, Li H, Zhao L, Luo Y, Zhu Z, Liu Y and Qu X Cetuximab-induced insulin-like growth factor receptor I activation mediates cetuximab resistance in gastric cancer cells. Mol Med Rep 11: 4547-4554, 2015.

52. Rebucci M, Peixoto P, Dewitte A, Wattez N, De Nuncques MA, Rezvoy N, Vautravers-Dewas C, Buisine MP, Guerin E, Peyrat JP, et al: Mechanisms underlying resistance to cetuximab in the HNSCC cell line: Role of AKT inhibition in bypassing this resistance. Int J Oncol 38: 189-200, 2011.

53. Troiani T, Napolitano S, Vitagliano D, Morgillo F, Capasso A, Sforza V, Nappi A, Ciardiello D, Ciardiello F and Martinelli E: Primary and acquired resistance of colorectal cancer cells to anti-EGFR antibodies converge on MEK/ERK pathway activation and can be overcome by combined MEK/EGFR inhibition. Clin Cancer Res 20: 3775-3786, 2014.

54. Bianco R, Rosa R, Damiano V, Daniele G, Gelardi T, Garofalo S, Tarallo V, De Falco S, Melisi D, Benelli R, et al: Vascular endothelial growth factor receptor-1 contributes to resistance to anti-epidermal growth factor receptor drugs in human cancer cells. Clin Cancer Res 14: 5069-5080, 2008.

55. Leto SM and Trusolino L: Primary and acquired resistance to EGFR-targeted therapies in colorectal cancer: Impact on future treatment strategies. J Mol Med (Berl) 92: 709-722, 2014.

56. Wheeler DL, Huang S, Kruser TJ, Nechrebecki MM, Armstrong EA, Benavente S, Gondi V, Hsu KT and Harari PM: Mechanisms of acquired resistance to cetuximab: Role of HER (ErbB) family members. Oncogene 27: 3944-3956, 2008.

57. Iida M, Brand TM, Campbell DA, Starr MM, Luthar N, Traynor AM and Wheeler DL: Targeting AKT with the allosteric AKT inhibitor MK-2206 in non-small cell lung cancer cells with acquired resistance to cetuximab. Cancer Biol Ther 14: 481-491, 2013.

58. Kim SM, Kim JS, Kim JH, Yun CO, Kim EM, Kim HK, Solca F, Choi SY and Cho BC: Acquired resistance to cetuximab is mediated by increased PTEN instability and leads cross-resistance to gefitinib in HCC827 NSCLC cells. Cancer Lett 296: 150-159, 2010 . 